\begin{tabular}{llllllllll}
\hline & E & $\mathbf{D}$ & $\mathbf{I}$ & $\mathbf{T}$ & $\mathbf{O}$ & $\mathbf{R}$ & $\mathbf{I}$ & $\mathbf{A}$ & $\mathbf{L}$ \\
\hline
\end{tabular}

\title{
Does a Journal Have an Ethical Monitoring Duty?
}

\author{
Antony Porcino, PhD, HSI, \\ Executive Editor, IJTMB \\ CARE Research Program, Pediatrics, Faculty of Medicine \& Dentistry, University of Alberta, Alberta, Canada
}

\begin{abstract}
Research and ethics are inseparable. Based on abhorrent research abuses under the cloak of scientific enquiry, development of the process for the ethical overview of research on/with humans was undertaken. By the end of the twentieth century, sufficient and extensive local and international principles, guidelines, legislations, and treaties about research on humans were in place, with all human-based research requiring review by independent research ethics committees (RECs). With so much established knowledge and legislation about the ethical management of the research process and REC oversight, is there a role for journal editorial boards in ethical oversight? Recommendations from the International Committee of Medical Journal Editors, the basis of the editorial policies of the IJTMB, include the requirement that research must be approved by an REC, and documentation of that review should be included in each article. Thus, as a minimum, journals must ensure that any research submitted for publication has had appropriate ethical review. But journals receive manuscripts after research is done. Journals, therefore, have a duty to ensure that received manuscripts meet expected standards for the publication of research and, for nonresearch situations, that appropriate protections of the research participants were in place even though REC review was not involved.
\end{abstract}

Research and ethics are inseparable. By the end of the twentieth century, the development of the ethical overview of research seemed to be complete. We had learned from the Nazi's abuse of humans for testing ideas, theories, and treatments on humans (for details, see the Nuremburg Code and the Declaration of Helsinki). The medical abuse of the black males of Tuskegee in the USA (www.cdc.gov/tuskegee/ timeline.htm) and the non-consensual, colonialist research on - rather than consensual, respectful research with-aboriginal peoples (http://ahrnets.ca/ files/2010/05/ethics_review_iphrc.pdf) have further shaped our understanding of the breadth and depth of potential ethical issues under the cloak of scientific enquiry. Such lessons have resulted in on-going refinement of local and international principles, guidelines, legislations, and treaties about research on humans.

Any research on humans now requires review by independent research ethics committees (RECs), such as Research Ethics Boards (REBs) and Institutional Review Boards (IRBs). These boards ensure the research has scientific and social value, that informed consent from participants is received, that the privacy of the participants is safeguarded, and that the research is fair, equitable, and meets expectations of social justice - thereby reducing biases of race, gender, and social status.

With so much established knowledge and legislation about the ethical management of the research process, is there a role for journal editorial boards in ethical oversight? Recommendations from the International Committee of Medical Journal Editors, the basis of the editorial policies of the IJTMB, include the requirement that all research must be approved by an REC and documentation of that review should be included in each article. All IJTMB articles have statements about their ethical oversight or informed consent process. Look for this ethical information in the Methods section of IJTMB research and case report articles.

The defining question for the IJTMB is, "When is a project considered research that falls under the REC purview?" This has important ramifications for a journal such as IJTMB because: 1) it affects what we expect to see, yet researchers may not be clear if their project is defined as research (e.g., educational evaluations, surveys, case reports, single subject design); and 2) there are financial and logistical barriers to REC access for our profession. The IJTMB has a duty to uphold international interpretation of research in the former, and an obligation to increase awareness of the latter.

The crux of the REC purview issue centers on the question, "What is research?" Interpretation and application of ethics relies on internationally established foundational principles, such as from the WHO (www.who.int/ethics/research/en). In Canada, federal 
government policy defines research as "an undertaking intended to extend knowledge through a disciplined inquiry or systematic investigation". (1) In the USA, the definition is even more simple, "A systematic attempt to develop new knowledge".(2) Any research involving humans that meets the above definitions - or the nature and intent of those definitions-will require REC review. The definition of research does not discriminate about the type of research, and any project with human subjects, from clinical trials to surveys, requires the same ethical overview.

The various international guidelines, and thence countries' policies, also set out the exceptions to mandatory REC review. Exceptions relevant to massage and bodywork include some forms of educational evaluations, quality assurance, and case reports. The first two are usually exempt because they are used internally to an organization, not for general knowledge development. REC review is often needed if there are any plans for publication (which would be an extension of knowledge outside the applicable organization). RECs cannot review retroactively, so if publication may be considered, REC review at the outset is best, rather than later when the author may be confronted with limited publication and presentation opportunities. Note that these types of research will usually qualify for expedited review. Case reports do not require REC oversight because they are not planned as experiments; when published, they share experience about interesting cases that occur as part of general and usual practice. Note however, that the usual consent processes are still needed for treatment, and the publication of case reports will need very specific informed consent, involving components such as statements about the management of confidentiality in the writing and approval of any images used (or consent if the individual would prefer identification), and how consent was obtained, for example. The Committee on Publication Ethics has recently published an updated Discussion Document on Best Practice for Publishing Medical Case Reports, and its use is highly recommended. Some singles-subject research trials may be borderline case reports, involving preplanning experimental conditions either for clinical care or research purposes and, because of this potential care/research cross-over, some RECs require review no matter the scenario.

The IJTMB strongly encourages practitioner-based research, and many projects-including gathering knowledge about the profession-can be done without university, university-affiliated, or medical institution involvement, but not without REC review. Unfortunately, the need for REC review can create a significant barrier because REC reviews cost money. Ethical review services are usually offered for free to members of institutions with an REC affiliation. Under some conditions, some RECs may offer reviews for free externally, but if the research is "industry sponsored" or sponsored by a "for-profit", which may be interpreted as practitioners and their businesses, there are fees, likely several thousand dollars. Your situation would need to be reviewed by your local REC. Therefore, collaboration with academic-based persons or engaging with your REC in the planning stages is necessary. Critically, even if practitioners are not aware of the need for REC review, without it their research must, ethically, be refused for publication by a journal like the IJTMB. The IJTMB has an explicit statement about this possible scenario, and has had to apply it several times in the last year.

Finally, the editors of the IJTMB recognize that much can happen between the undertaking of research and the submission of a manuscript to the Journal. Was an REC notified of all issues arising during the research? How thorough was the informed consent process for the case report? Were all privacy and confidentiality processes managed appropriately? A journal is not in the position to police such issues. But it cannot ignore them either, and must remain vigilant in ascertaining that received manuscripts sufficiently show that appropriate ethical and consent steps were taken throughout the research process and in the preparation of the submitted manuscript. Anything less would be unethical.

\section{COPYRIGHT}

Published under the CreativeCommons AttributionNonCommercial-NoDerivs 3.0 License.

\section{REFERENCES}

1. Govt. of Canada, Panel on Research Ethics. TCPS 2 (2014) Tri-Council Policy Statement: Ethical Conduct for Research Involving Humans. Ottawa: PRE; 2014. Available from: http:// www.pre.ethics.gc.ca/eng/policy-politique/initiatives/tcps2eptc2/Default/

2. National Institutes of Health. Glossary of Commonly Used Terms in Research Ethics. Research Triangle Park, NC: National Institute of Environmental Health Sciences, 2015. Available from: http://www.niehs.nih.gov/research/resources/ bioethics/glossary/index.cfm

Corresponding author: Antony J. Porcino, BSc, $\mathrm{PhD}$, HSI, CARE Research Program, Pediatrics, Faculty of Medicine \& Dentistry, University of Alberta, 8B16A 11111 Jasper Avenue, Edmonton, Alberta, Canada T5K 0L4

E-mail: eeitjmb@gmail.com 